Editorial

\title{
Special Feature Development and Application of Optical Coherence Tomography (OCT)
}

\author{
Michael Pircher* \\ Center for Medical Physics and Biomedical Engineering, Medical University of Vienna, Waehringerguertel 18-20, \\ 1090 Vienna, Austria
}

Received: 8 October 2017; Accepted: 12 October 2017; Published: 13 October 2017

\section{Introduction}

To celebrate the 25th anniversary of the introduction of OCT, the special feature issue entitled "Development and Application of Optical Coherence Tomography (OCT)" had been initiated. OCT originated from low coherence interferometry [1] and was adapted for tomographic imaging in 1991 [2]. In OCT, broad bandwidth light is used in order to produce cross-sectional images of turbid and translucent samples with high axial resolution (in the order of a few $\mu \mathrm{m}$ ). Thereby, the imaging speed of OCT can be as high as several millions of depth scans (A-scans) per second, which allows for volumetric investigations of dynamic processes [3]. Nowadays, OCT can be regarded as a well-established technique that offers various applications in different fields. Some of these applications and latest developments are covered in the special feature issue, consisting of three overview papers and nine research papers. These are outlined below in the order of their appearance in the feature issue.

The high imaging speed of OCT enables the contrasting of dynamic structures (e.g., blood vessels) from static tissue. Thereby, two or more cross-sectional OCT tomograms (B-scans) are recorded at the same sample location at high speed. Any motion introduced by flow will cause changes of the amplitude and phase between the recorded OCT B-scans. As a result, vessel maps of tissue are generated and the technique is referred to as OCT angiography (OCTA), mainly because of the similarity of the images to conventional angiographic imaging. However, in contrast to most angiographic techniques, OCTA is completely non-invasive and does not rely on the administration of contrast agents. J. Zhu et al. [4] present an overview on the various algorithms used for OCTA and provide a detailed analysis on the question of whether the technique can be extended from a purely contrasting method to a more quantitative assessment of the underlying flow.

By exploiting the polarization sensitive information carried by light, additional information on sample composition can be obtained. The corresponding technique is called polarization sensitive (PS-)OCT, which enables the contrasting of different tissue types based on their polarization sensitive properties. PS-OCT is not limited to the biomedical field, and can be very attractive for material sciences and non-destructive testing. Technological principles as well as the various applications of PS-OCT are summarized by B. Baumann [5].

An interesting and growing field of application for OCT is presented by $\mathrm{H}$. Schneider et al. [6]. In their work, they provide an overview of OCT in dentistry and evaluate the performance of the technique for caries diagnosis and for the monitoring of composite restorations.

OCT-based image-guided surgery is another growing field of application. Thus, fast imaging processing will be essential for translating this technology to clinical routine. In order to address this issue, M. Zhou et al. [7] present new segmentation approaches for localizing surgical needles that can be inserted into the eye ball for microsurgical procedures.

The sintering process is an important step towards high quality fabrication of tooth prostheses. State of the art quality metrics of this process are either time-consuming or subjective. 
C. Sinescu et al. [8] propose the use of OCT for a non-destructive investigation of temperature effects during this process.

For specific applications, the image contrast provided by OCT might not be sufficient. To increase the visibility of structures, contrast agents can be employed that are usually highly scattering. A very elegant method is the use of iron oxide particles in combination with magnetic-induced motion of the particles. The corresponding technique is referred to as magnetomotive-OCT (MM-OCT). In their paper, P. Cimalla et al. [9] present an improved method for MM-OCT and provide first imaging results in cells. Doppler OCT enables the non-invasive quantification of flow in tissue by measuring the axial velocity component. However, lateral motion may influence the corresponding quantitative data. With the aim of minimizing this influence, J. Walther et al. [10] extend the concept of resonant Doppler OCT by moving the OCT scanning unit lateral to the sample.

Protective coatings are very important for various objects. Corresponding thickness measurements are essential for determining the quality and degradation of coatings. The ability of OCT in comparison with state of the art methods for determining degradation effects are presented by M. Lenz et al. [11]. Coating thickness measurements for the automotive industry using a line field OCT approach are presented by S. Lawmann et al. [12].

As outlined above, dynamic processes can be investigated using OCT because of the fast imaging speeds provided by the technique. These dynamic processes may occur at different time scales and are investigated in two papers of the special issue. C. Schnabel et al. [13] use OCT to investigate the rather fast alveolar dynamics in an in vivo animal model. On the other hand, O. Thouvenin et al. [14] use full field OCT in combination with dynamic, mechanical, and molecular contrast with the aim of providing tissue- and disease-specific information on a microscopic level and improving the sensitivity/specificity of disease diagnosis. The depth range of spectral domain OCT instruments is generally limited and may not be sufficient for a specific application. For an extension of this depth range, T. Wu et al. [15] use two separate reference arms in combination with a phase modulation. The latter allows the reconstruction of the full complex signal and a doubling of the depth range, which is doubled again through the implementation of the second reference arm.

With all these contributions, this special feature issue underlines the very active and rapidly growing field of OCT. Meanwhile, various applications of the technology have been demonstrated and further improvements of instrumentation may be developed in the future. This may pave the way for additional applications of this powerful imaging technique.

Acknowledgments: I would like to take this opportunity to thank all the authors for their contribution to this special feature issue. In addition, I would like to thank the reviewers for their time and efforts in reviewing the manuscripts. Reviewing can very often be a thankless task, but I believe that it represents an essential part of the scientific publishing process as it significantly improves the overall quality of the papers that are published. Finally, I would like to acknowledge the hard work of the organizational and editorial team of Applied Sciences. Without their excellent support this special feature issue would not have been possible.

Conflicts of Interest: The author declares no conflict of interest.

\section{References}

1. Hitzenberger, C.K.; Drexler, W.; Leitgeb, R.A.; Findl, O.; Fercher, A.F. Key Developments for Partial Coherence Biometry and Optical Coherence Tomography in the Human Eye Made in Vienna. Investig. Ophthalmol. Vis. Sci. 2016, 57, 460-474. [CrossRef] [PubMed]

2. Huang, D.; Swanson, E.A.; Lin, C.P.; Schuman, J.S.; Stinson, W.G.; Chang, W.; Hee, M.R.; Flotte, T.; Gregory, K.; Puliafito, C.A.; et al. Optical Coherence Tomography. Science 1991, 254, 1178-1181. [CrossRef] [PubMed]

3. Wieser, W.; Draxinger, W.; Klein, T.; Karpf, S.; Pfeiffer, T.; Huber, R. High definition live 3D-OCT in vivo: design and evaluation of a 4D OCT engine with 1 GVoxel/s. Biomed. Opt. Express 2014, 5, $2963-2977$. [CrossRef] [PubMed]

4. Zhu, J.; Merkle, C.W.; Bernucci, M.T.; Chong, S.P.; Srinivasan, V.J. Can OCT Angiography Be Made a Quantitative Blood Measurement Tool? Appl. Sci. 2017, 7, 687. [CrossRef] 
5. Baumann, B. Polarization Sensitive Optical Coherence Tomography: A Review of Technology and Applications. Appl. Sci. 2017, 7, 474. [CrossRef]

6. Schneider, H.; Park, K.J.; Hafer, M.; Ruger, C.; Schmalz, G.; Krause, F.; Schmidt, J.; Ziebolz, D.; Haak, R. Dental Applications of Optical Coherence Tomography (OCT) in Cariology. Appl. Sci. 2017, 7, 472. [CrossRef]

7. Zhou, M.; Roodaki, H.; Eslami, A.; Chen, G.; Huang, K.; Maier, M.; Lohmann, C.P.; Knoll, A.; Nasseri, M.A. Needle Segmentation in Volumetric Optical Coherence Tomography Images for OphthalmicMicrosurgery. Appl. Sci. 2017, 7, 748. [CrossRef]

8. Sinescu, C.; Bradu, A.; Duma, V.F.; Topala, F.; Negrutiu, M.; Podoleanu, A.G. Effects of Temperature Variations during Sintering of Metal Ceramic Tooth Prostheses Investigated Non-Destructively with Optical Coherence Tomography. Appl. Sci. 2017, 7, 552. [CrossRef]

9. Cimalla, P.; Walther, J.; Mueller, C.; Almedawar, S.; Rellinghaus, B.; Wittig, D.; Ader, M.; Karl, M.O.; Funk, R.H.W.; Brand, M.; Koch, E. Improved Imaging of Magnetically Labeled Cells Using Rotational Magnetomotive Optical Coherence Tomography. Appl. Sci. 2017, 7, 444. [CrossRef]

10. Walther, J.; Koch, E. Flow Measurement by Lateral Resonant Doppler Optical Coherence Tomography in the Spectral Domain. Appl. Sci. 2017, 7, 382. [CrossRef]

11. Lenz, M.; Mazzon, C.; Dillmann, C.; Gerhardt, N.C.; Welp, H.; Prange, M.; Hofmann, M.R. Spectral Domain Optical Coherence Tomography for Non-Destructive Testing of Protection Coatings on Metal Substrates. Appl. Sci. 2017, 7, 364. [CrossRef]

12. Lawman, S.; Williams, B.M.; Zhang, J.; Shen, Y.C.; Zheng, Y. Scan-Less Line Field Optical Coherence Tomography, with Automatic Image Segmentation, as a Measurement Tool for Automotive Coatings. Appl. Sci. 2017, 7, 351. [CrossRef]

13. Schnabel, C.; Gaertner, M.; Koch, E. Optical Coherence Tomography (OCT) for Time-Resolved Imaging of Alveolar Dynamics in Mechanically Ventilated Rats. Appl. Sci. 2017, 7, 287. [CrossRef]

14. Thouvenin, O.; Apelian, C.; Nahas, A.; Fink, M.; Boccara, C. Full-Field Optical Coherence Tomography as a Diagnosis Tool: Recent Progress with Multimodal Imaging. Appl. Sci. 2017, 7, 236. [CrossRef]

15. Wu, T.; Wang, Q.Q.; Liu, Y.W.; Wang, J.M.; He, C.J.; Gu, X.R. Extending the Effective Ranging Depth of Spectral Domain Optical Coherence Tomography by Spatial Frequency Domain Multiplexing. Appl. Sci. 2016, 6, 360. [CrossRef] 